\title{
Research on the Overall Teaching Quality System of Medical Building Universities Based on TQC
}

\author{
Chune LIANG ${ }^{1}$, Bo LIANG ${ }^{1}$, Xue ZHOU ${ }^{1}$, Yueli XIANG ${ }^{1}$, Miaojing LI ${ }^{1}$, Xue mei LI $^{1 *}$ \\ ${ }^{1}$ Mudanjiang Madical University, Mudanjiang 157011, P.R.China \\ A402269994@QQ.com \\ *Corresponding author
}

\begin{abstract}
TQC teaching of medical universities which aims at the teaching goal is a process of systematical analysis and overall control to various internal and external factors affecting the quality of classroom by establishing QC teams of all levels and applying the thinking mode, method and means of TQC. This paper explores the constructive principles of TQC teaching system in medical universities and the basic formation of TQC system. The general principle of TQC in medical universities is the advanced and feasible quality target, full participation and implementation, scientific and effective control method and accurate and timely information feedback. The TQC teaching is made up of related subsystems, with each subsystem completing the corresponding PDCA cycle and through the QC team to ensure the achievement of each subsystem's goal, thus guaranteeing the realization of the general goal of TQC system.
\end{abstract}

Keywords-TQC; Teaching Quality; QC Team; Object System

\section{INTRODUCTION}

To implement a comprehensive control of classroom teaching in medical colleges and universities, we should apply the basic theory of modern management, consider the features of teaching in the new period and follow some certain principles of construction to establish scientific and practical TQC teaching system

\section{CONSTRUCTION OF TQC TEACHING SYSTEM}

TQC classroom teaching is a systematic project, based on the educational goals of medical colleges, It makes a comprehensive analysis of various factors affecting the teaching quality, establish an overall control system of teaching quality and applies PDCA cycle and the corresponding control means and methods to ensure the realization of goal of classroom teaching system. In the process of TQC teaching system construction, the establishment of quality - target system is the starting point and key to TQC system project; the formation of managing and organizational system of classroom teaching quality is the guarantee of TQC system engineering; the mode and means of control in teaching quality is its core and the managing system of teaching quality information is its support.

\section{A. Object System}

Firstly, make sure the overall goal of quality in classroom teaching system. This goal should be consistent with the educational goals of medical colleges. Meanwhile, it is not only scientific and advanced but also incentive and feasible. The goal of TQC teaching should be established based on. fully analysis in many factors such as teaching object, teaching target, teaching environment and resources, etc. Secondly, fully analyze all factors which affect the teaching quality, decompose these factors according to the classroom teaching process and classroom monitoring organization system, identify the control object of each component and form a comprehensive and complete teaching quality system. Thirdly, clarify the definition of overall objective and each sub-objective, quality the indicators as much as possible so as to analyse and examine.

We should sufficiently consider the features of medical major ,teaching conditions, combination of theory classes and practice classes and teaching targets, to improve and guarantee the effectiveness of TQC target system on a scientific and feasible basis.

\section{B. Organization System}

The managing system of teaching quality and monitoring system ensure the implementation of the TQC system objectives. Therefore, establishing a scientific, perfect TQC system and monitoring system is the precondition of the smooth PDCA circulation. The traditional teaching-quality monitoring system often emphasizes the compulsory control, which lack of initiative and active participation. However, TQC teaching stresses the comprehensiveness and initiative of quality management. Therefore, not only the teachers serving as the main body of classroom should play a dominant role, but also. The related everyone should actively take part in the classroom teaching quality control. The students being the direct beneficiaries of TQC are also the participants. As a result, on the construction of organization system, school, department and research section not only establish the threelevel managing organization, but also form the corresponding

Quality circle at each basic unit or key point, namely QC team. According to the voluntary principle, we can organize QC activities. As for the building of system, we should highlight the characteristics of the monitor of society, school 
supervision, department and research section and selfassessment and mutual assessment of teachers and the students' evaluation.

\section{Control System}

Control subsystem is a system about TQC classroom teaching goal, which makes a comparative analysis of the practical conditions of quality control factors and control standards, writes the control report and puts forward the corresponding measures of improvement and suggestion by establishing control system and employing corresponding control method and mode. This subsystem is the core of the whole system operation in TQC system, which is the necessary process to realize the target of teaching system. The principle of formation as follows (eg: Fig 1):

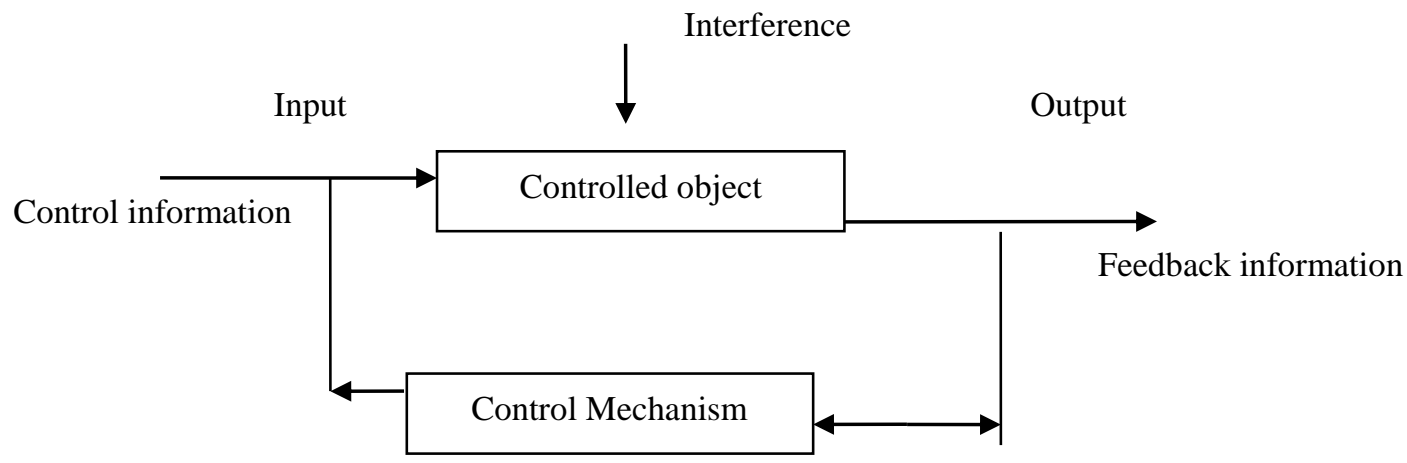

Fig. 1 The principle of control subsystem

In the classroom teaching by teachers, everything from teaching preparations (writing lesson plans, formulation teaching plans, preparing teaching method, etc) to the implementation of classroom teaching and teaching evaluation should be performed according to the regulations of teaching, which means it should achieve the first purpose of classroom teaching, that is to say the basic objective of controlling work is to maintain the status quo. In the changeable teaching environment, we should compare the result with standard at anytime through control, once finding deviation, we need to take timely measures to make the activities of teaching system stab to achieve the planned goal of teaching management. In some cases, change teaching environment puts forward some new requirements on the classroom teaching system, the teaching supervisor or the teachers may be dissatisfied with the teaching status quo, thus implement the teaching reform.

Conduct teaching innovations and create a new situation of teaching. In this way, it is necessary to break the status quo, to determine the New classroom teaching goals and control standards of TQC and to make it more advanced and reasonable.

\section{Management Information System}

The information management system of classroom teaching TQC mainly includes the hardware and software of TQC information management, and human resources to meet the needs of supporting teaching system information and correspondence. The way to distinguish the information system of classroom management and management system of TQC classroom teaching is functions and service objects in the system of teaching. The information system of teaching management can meet the need of supporting daily teaching management, and at the same time, ensure the minimum-level function of teaching management. The information management system of TQC classroom teaching supports higher levels of teaching quality management and the strategic need of teaching reform.

The information management system of TQC classroom teaching, from the analysis and establishment of object, formulation of system building of organization, control of the plan implementation to the evaluation and analysis of each link of the PDCA cycle, complete the feed forward control the searching, processing and transmitting the information.

\section{BASIC CONTENTS TO CONTROL THE CLASSROOM TEACHING QUALITY}

Classroom teaching quality control is an important part of the TQC classroom teaching, the purpose of which is, after the inspection and analysis of classroom teaching quality, to take effective measures to control the adverse factors, adjust the working procedures, make the wrong things no longer spread, and solve the problem in the initial state.

\section{A. Control the teaching plan}

Teaching plan is the main factors affecting the classroom teaching. The teaching plan, weather made by the nation or by the school, should be carried out once approved. Anyone can't change it and must organize and direct classroom teaching according to lesson plans to guarantee normal operation of teaching classroom teaching, guarantee normal operation of job of teaching.

\section{B. Control the teaching process}

We should graspt the quality of every teaching link in the teaching process with the unified standard of quality, carries forward the achievement, strengthen the weak links, control the adverse factors and make the teaching process form a strict quality control line to facilitate the operation of teaching work in a high-quality, high-effectiveness and high-standard way. 


\section{Control the teaching conditions}

We should optimize the teaching conditions, the teaching instruments and equipments bases, books and materials, the teaching environment as far as possible according to school's human resources, finance and power, to control human factors worsening teaching conditions.

\section{Control the quality of teaching staff}

The focus is to inspect and manage the staff's qualification. The teaching demonstration system is practiced for the new teachers, with school supervious, departments and research teams on guard.

\section{E. Control the management system}

The focus should be placed on the responsibility and rewards system. The responsibility system centers on teaching, concerning improve the teaching quality of classroom, Different departments and their staff take on different duties.

Teachers shoulder the duties of teaching and management; Students of learning and development, departments of service and cultivation, and leaders of direction and management, which means identifying fulfilling and being responsible for each duty.

The rewards and punishment system is to reward the staff who make the greatest contributions to improving the quality of classroom teaching in the light of the principle combining duty, power and benefit, like establishing outstanding teaching achievement prize, teaching research prize, excellent academic performance prize, etc.

\section{SUMMARY}

Establish overall quality of classroom teaching, formulating quality control standard for classroom teaching, carrying out inspection of teaching quality, conducting analysis of teaching quality and implementing control on teaching quality make up the complete and tight control system of TQC classroom teaching system.

\section{ACKNOWLEDGEMENT}

This research was financially supported by the 2014Humanities and social science project of Heilongjiang Province (No.12542298) .

\section{REFERENCES}

[1] Ting Chen, Fengrong Yang, To improve the effective way of teaching quality in medical colleges and universities. Medical Education Research and Practice, 2, (2008)219-220.

[2] Lina Zou, Shengzhong Rong, Miaojing Li, To survey and influencing factors of grass-roots employment of Medical students, Soft Science of Health, 7, (2014)459-461.

[3] Feiyu Chen, Enxian Fu, to improve the teaching quality method of innovation and entrepreneurship in medical colleges and universities, Guide to Business, 19, (2016)121.

[4] Donghua Lin, Undergraduate course personnel training reform thinking and practice, Education Modernization, 3, (2016)64-65.

[5] Hongqing An, Xiao Yang, Aiqin Zhang, Analysis of occupational identity of medical students in medical school., China Higher Medical Education, 10, (2016)38-39. 